\section{A hybrid-fuzzy TOPSIS method to analyze the consumption and buying behavior of fishery and aquaculture products (FAPs) in the EU28}

\author{
Javier Cantillo, Juan Carlos Martin and Concepción Román \\ Institute of Tourism and Sustainable Economic Development, \\ University of Las Palmas de Gran Canaria, Las Palmas de Gran Canaria, Spain
}

Consumption and buying behavior of FAPs in EU28

Received 1 December 2019 Revised 9 December 2019 Accepted 2 January 2020

\begin{abstract}
Purpose - The purpose of this investigation is to develop a hybrid fuzzy TOPSIS methodology in order to understand in a practical and integrated way, the consuming and buying behavior of EU residents towards Fishery and Aquaculture Products (FAPs), with an emphasis in the consumption and buying frequency.

Design/methodology/approach - Data were obtained from the Special Eurobarometer Survey (European Union, 2018b), which is a survey of $27,732 \mathrm{EU}$ residents with different socio-demographic characteristics that represent the $28 \mathrm{EU}$ countries. A hybrid fuzzy TOPSIS methodology that synthesizes the consuming and buying behavior of the EU residents toward FAPs was developed.

Findings - The results show that among the countries, Spain has the highest consumption and buying patterns of FAPs, while among the generations it corresponds to the residents born between 1928 and 1945. In addition, there are important differences that depend on the country of residence as well as the generation of the residents. The elasticity analysis evidenced that marketing strategies would have the biggest impact in the countries located in the Central-Eastern zone of the EU and on the generation formed by the people born after 1980.

Originality/value - Although in the literature there are many studies that aimed to understand the behavior of consumers for FAPs, few investigations have focused on analyzing and integrating both the consumption and buying behavior, and to our best knowledge, there are no studies providing a methodology that allow making comparisons between different countries regarding the consumption and buying behavior of FAPs.
\end{abstract}

Keywords Fuzzy logic, Triangular fuzzy numbers, TOPSIS, Fishery and aquaculture products, FAPs, Residents' consuming and buying behavior, EU28

Paper type Research paper

\section{Introduction}

According to FAO (2018), in 2013, the global consumption of fish was estimated around $19.8 \mathrm{~kg}$ per capita, representing around $17 \%$ of the global population's intake of animal proteins; while estimates for 2016 showed further growth of around $20.3 \mathrm{~kg}$ per capita. Particularly, for the EU, consumption of fishery and aquaculture products (FAPs) per capita was higher, being around $24.3 \mathrm{~kg}$ for 2016 (European Union, 2018a).

\footnotetext{
C Javier Cantillo, Juan Carlos Martin and Concepción Román. Published by Emerald Publishing Limited. This article is published under the Creative Commons Attribution (CC BY 4.0) licence. Anyone may reproduce, distribute, translate and create derivative works of this article (for both commercial and noncommercial purposes), subject to full attribution to the original publication and authors. The full terms of this licence may be seen at: http://creativecommons.org/licences/by/4.0/legalcode

Funding: This work is part of a project that has received funding from the European Union's Horizon 2020 research and innovation programme under the Marie Skłodowska-Curie grant agreement No. 766347.
}

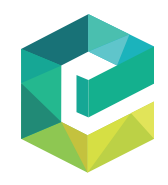

British Food Journal Emerald Publishing Limited DOI 10.1108/BFJ-12-2019-0884 
The EU represents the largest trader of FAPs in nominal terms of the world (FAO, 2018). Most of these trade flows are imports that cover around $70 \%$ of the consumption of European residents.

Understanding consumer habits for FAPs is necessary for policymakers and aquaculture producers to plan their market strategies. In addition, understanding these attitudes towards FAPs facilitates an appropriate implementation of the common fisheries policy, which aims to balance different stakeholders involved in the market in order to guarantee the sustainability of FAPs for EU citizens.

This investigation develops a hybrid fuzzy TOPSIS methodology in order to understand in a practical and integrated way, the consuming and buying behavior of EU residents towards FAPs, with an emphasis in the consumption and buying frequency, which can predict in an effective way product preference (Kumar et al., 2008; Quagrainie, 2006). It is important because it is well known that frequent buyers of FAPs have usually as well the higher willingness to pay for them (Quagrainie, 2006).

Based on the Eurobarometer survey on EU consumer habits related to FAPs, a synthetic demand indicator for the consumption of FAPs discriminating by country and generation is calculated. Finally, elasticities associated with the synthetic demand indicator with respect to each attribute for all EU countries and generation are calculated, and some policy implications are discussed.

Thus, the aim of this investigation is four-fold: (1) to extend the current literature with the proposal of a methodology that integrates both the consumption and buying behavior of the EU residents and that obtains a synthetic demand indicator for FAPs; (2) to compare the obtained synthetic indicator by countries and generation; (3) to analyze whether the indicator is more or less sensitive to consumption or buying attributes; and (4) to discuss the main policy implications derived from the results to support the implementation of the common fishery policy.

The rest of the paper has the following structure: Section 2 presents a summary of the relevant literature review associated with the topic, Section 3 describes the data used for the estimation of the methodology, Section 4 explains the methodology proposed, Section 5 describes the application of the methodology and highlights the main results, Section 6 presents a discussion of the results, and finally, Section 7 concludes.

\section{Literature review}

The literature review evidences different methodological approaches with the objective of understanding the frequency of consumption of different seafood products: theory of planned behavior as a conceptual framework and structural equation models, probit and logit models, regressions and other statistical analyses. In this section, each methodology is presented with the main findings of some papers related to them.

\section{Theory of planned behavior as a conceptual framework and structural equation models}

For the context of Lima, Peru, Higuchi et al. (2017) found that personal attitudes, past experiences and norms influenced positively the intention to eat fish, which similarly influenced positively the frequency of fish consumption. Moreover, Tomic et al. (2016) for Croatian consumers and, Tuu et al. (2008) and Thong and Olsen (2012) for Vietnamese consumers found that the attitude was the most important predictor of the intention to consume fish and that the frequency of consumption of fish was highly correlated with the intention to consume it and with the perceived behavioral control.

In Belgium, Verbeke and Vackier (2005) found that a positive attitude, a high subjective norm and high perceived behavioral control had a positive impact on both the intention to eat fish and the frequency of consumption. Also, the results indicated that the fish consumption frequency was higher on women, people aged over 40 and living in coastal regions. 
Yousuf et al. (2019), in Oman, concluded that nationals, members of smaller household size and fresh fish consumers were more likely to consume fish, while lower-income consumers and those who are habit persistent were more eager to purchase fish more frequently.

Rortveit and Olsen (2007) for Danish consumers, found that the consideration set size (number of fish alternatives) had a positive effect on the consumption frequency; and that attitude and especially knowledge impacted positively and directly on the consumption frequency of fish, and indirectly through set size. Similarly, Rortveit and Olsen (2009) in Norway found that the biggest impact on the consumption frequency was given by the attitude towards fish; while convenience orientation (consumer's desire to save time and energy in food preparation) and perceived product inconvenience (personal beliefs related to fish) had a negative direct effect on the consideration set size, the attitude towards fish and the consumption frequency.

\section{Probit and logit models}

In South Korea, Lee and Nam (2019) found that respondents with low demand price elasticity and those who consider safety as more relevant than price were likely to consume live fish more frequently. Also, interestingly, although wild-caught fish preference was relevant to consumers' choice, it was insignificant for their consumption frequency.

Moreover, in the context of farm-raised catfish in the US, Kumar et al. (2008) found that fresh catfish buyers, married couples, Caucasians and African Americans had a higher probability of purchasing it more frequently; while positive opinions, the origin of the catfish product labels and vacuum-sealed packaging influenced the frequency of purchase.

Myrland et al. (2000), based on a data set of Norwegian women from 30 to 44 years involved in a medical study, concluded that the product attributes were more important perceived barriers for consumption, rather than beliefs concerning price. In addition, the consumption was increased when individuals were older, had higher education or bigger household size.

Likewise, Thong and Solgaard (2017), in France, found that old and high-income consumers consumed seafood more frequently; while the presence of kids in the households had a significant effect on shrimp consumption, but not for fish and mussels. In addition, among nine motives evaluated in reference to fish consumption frequency, the most important ones were weight control (low in fat and calories) and convenience (easiness to prepare), being the first a positive driver and the second a barrier for consuming the studied products.

Santeramo et al. (2017), analyzing the oysters' market in Italy, found that consumers who were used to eating them had a frequent consumption. Similarly, there was a higher frequency of consumption for consumers who cared about the safety of oysters and were experts on judging oyster's safety, as well as for those who cared about environmental issues.

In the context of the northeast coast of Mexico, Almendarez-Hernández et al. (2015) found that consumers that preferred canned tuna have a lower frequency of consumption in comparison to those that preferred fresh tuna.

\section{Regressions}

Cavaliere et al. (2019) found that individuals with higher education, higher income, young, female and living with a partner, consumed fish more frequently. Moreover, Can et al. (2015), in a region of low fish consumption in Turkey, found that single persons, students and young people tended to have a bigger consumption level than their counterparts, while females also consumed more fish than males.

Herrmann et al. (1994), studying the north-eastern consumers of the United States, found that seafood purchases depend on attitudes toward fish, especially for the frequency of 
purchase at home. The authors identified that the main key drivers on at-home purchase frequency were white-collar occupation, older age, urban/suburban residence, New England location and recreational fishing participation; while the consumers associated with frequent restaurant purchase were likely those with the highest income, white-collar occupations, recreational fishing involvement and living in household with children age 10 or under.

\section{Other statistical analyses}

Other investigations have based their evaluation in common statistical analysis such ANOVA (Almeida et al., 2015), Spearman's correlation (Murray et al., 2017), frequency distribution (Islam et al., 2018; Vanhonacker et al., 2011) and factor analysis (Hall and Amberg, 2013; Islam et al., 2018)

Almeida et al. (2015), in the context of Portuguese consumers, found that more knowledgeable consumers had higher seafood consumption frequencies at home and were more interested in information about seafood products.

Moreover, Murray et al. (2017), in Canada, found that there was a significant but small correlation between childhood and adult consumption frequencies. Similarly, the age was positively slightly correlated with adult purchasing frequency, while the income and gender were not. The authors also found that adult purchase frequency was affected positively by consumers who purchased seafood because of its health benefits and nutritional value.

Vanhonacker et al. (2011) for some countries in Europe (Sweden, Germany, United Kingdom, Romania, Czech Republic, Portugal, Greece and Italy) concluded that for most of these countries, wild fish self-reported consumption was higher than farmed fish selfreported consumption, except for Germany, Romania and the Czech Republic.

Islam et al. (2018) in Bangladesh, noticed that fish was mostly consumed by cluster groups related to restaurant consumers and those characterized by a high level of awareness about quality and price ratio and food freshness, and highly concerned about the food and cuisine preference of other family members. The findings also showed that the average consumption for fish in Bangladesh was higher for men, upper-middle and upper social classes, living in households with the lesser family members, and with the educational level of secondary, higher secondary and bachelors.

Finally, Hall and Amberg (2013) in the US found that the price, freshness and familiarity were the most important factors for the seafood choices, however, these factors did not predict the consumption patterns. In addition, beliefs in the benefits of aquaculture were positively related to higher consumption of aquaculture products.

\section{The questionnaire and data}

The database used for this investigation comes from the Special Eurobarometer Survey (European Union, 2018b), which is a survey of 27,732 EU residents with different sociodemographic characteristics that represent the $28 \mathrm{EU}$ countries. The survey was executed between June and July of 2018 with the objective of understanding better the internal market of FAPs for the EU28.

On the Eurobarometer survey, there is a module compound of three questions related to the consumption and buying behavior of Europeans towards FAPs (Table 1). The first two questions assess the consumption behavior at home and at restaurants or other food outlets, while the third question is related to buying behavior. The responses for these questions, which go from 1 to 5 , according to the frequency of execution of the action from never to at least once a week, respectively, were the base for the methodology developed in the present study taking into account the socio-demographic characteristics of the surveyed residents. 


\section{Methodology}

This methodology is based on the fuzzy TOPSIS (Techniques for order preference by similarity of the ideal solution) method and the input needed in this particular study to apply this methodology consists in the frequencies of consumption of FAPs at home and at restaurant and other food outlets, as well as the frequencies of buying of those products (Table 1). The frequency answers are based on a linguistic scale which is vague and imprecise not suitable for quantitative analysis.

For this purpose, fuzzy sets are an important mathematical tool which allows transforming the values of this linguistic information into numbers for quantitative analysis. The triangular fuzzy numbers (TFNs) offer an alternative of simplicity and usefulness in representing the information in a fuzzy environment; and are composed by three parameters $(a, b, c)$, in which $b$ represents the most likely value of the designated frequency, while $a$ and $c$ indicate the smallest and largest possible values.

The first step for applying the methodology is to convert the responses related to the frequency of eating or buying FAPs (never, less than one year, several times a year but less than once a month, at least once a month but less than once a week, at least once a week) into TFNs. For this purpose, the frequencies are expressed into the numbers of occasions per year to eat or buy FAPs, as a set of TFNs (Table 2).

Then, in the second step, mean TFNs are calculated for each segment of analysis, which considers different categories of analysis $p$ (country, generation, place of buying and others) and different elements $s$ that constitute each one of the grouping categories (e.g. Spain or Italy for the country category). Also, the mean TFNs are grouped separately according to the criterion $q$.

Therefore, the mean TFN for an element $s$ that belongs to the category $p$ and is related to a criterion $q$, is calculated as the mean of the responses (transformed into fuzzy numbers) of interviewed individuals 1 to $n$ that belong to that particular segment of analysis (Eqn 1).

$$
\tilde{A}=\left(a_{s, p, q}, b_{s, p, q}, c_{s, p, q}\right)=\left(\frac{\sum_{i=1}^{n} a_{i, s, p, q}}{n}, \frac{\sum_{i=1}^{n} b_{i, s, p, q}}{n}, \frac{\sum_{i=1}^{n} c_{i, s, p, q}}{n}\right)
$$

where $s: 1, \ldots, s ; p: 1, \ldots, p$ and $q: 1, \ldots, q$
Consumption and buying behavior of

FAPs in EU28

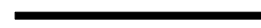

\section{.}


The third step of the methodology consists in estimating the crisp values per each segment of analysis $(s$ and $p$ ) and criterion $q$, by assigning a weight to each one of the components of the mean TFNs. For this investigation, the weights proposed by Chen (1996) were preferred because of its simplicity and objectivity as the method does not require prior judgements of experts. The crisp values indicate the annual frequency of consumption or buying of FAPs per each segment of analysis and criterion (Eqn 2).

$$
\mathrm{CV}_{s, p, q}=\frac{\left(a_{s, p, q}+2 \times b_{s, p, q}+c_{s, p, q}\right)}{4}
$$

where $s: 1, \ldots, s ; p: 1, \ldots, p$ and $q: 1, \ldots, q$

Then, the fourth step consists of determining the fuzzy ideal $\left(\mathrm{CV}_{q}^{+}\right)$and negative-ideal $\left(\mathrm{CV}_{q}^{-}\right)$solutions per criterion $q$, as the maximum and minimum crisp values per each criterion no matter the segment of analysis, as shown in Eqn 3. It is important to notice that the ideal solution is the one that maximizes the frequency of consumption or buying, which is the best situation for the market of FAPs, while the negative-ideal solution follows the opposite logic.

$$
\mathrm{CV}_{q}=\left\{\mathrm{CV}_{1,1, q}, \ldots, \mathrm{CV}_{s, p, q}\right\} \text { where } \mathrm{CV}_{q}^{+}=\max _{q}\left(\mathrm{CV}_{q}\right) \text { and } \mathrm{CV}_{q}^{-}=\min _{p}\left(\mathrm{CV}_{q}\right)
$$

where $s: 1, \ldots, s ; p: 1, \ldots, p$ and $q: 1, \ldots, q$

Then, the fifth step is to calculate the Euclidean distances (fuzzy distances) of each element of the segment of analysis in accordance with the ideal solutions (Eqn 4).

$$
d_{s, p}^{+}=\sqrt{\sum_{q=1}^{q}\left(\mathrm{CV}_{q}^{+}-\mathrm{CV}_{s, p, q}\right)^{2}} \text { and } d_{s, p}^{-}=\sqrt{\sum_{q=1}^{q}\left(\mathrm{CV}_{s, p, q}-\mathrm{CV}_{q}^{-}\right)^{2}}
$$

where $s: 1, \ldots, s$ and $p: 1, \ldots, p$

After that, the sixth step is to estimate consumption and buying synthetic indicators (CBSI) by the segment of analysis and rank the elements according to them per each group category. To accomplish this, the fuzzy distances calculated in the previous step are used to estimate the fuzzy closeness coefficient per element as shown in Eqn 5, which represents simultaneously the distances to the ideal and negative-ideal solutions.

$$
\mathrm{CBSI}_{s, p}=\frac{d_{s, p}^{-}}{d_{s, p}^{+}+d_{s, p}^{-}} \text {with } s: 1, \ldots, s \text { and } p: 1, \ldots, p
$$

Finally, the seventh and final step consists in estimating the elasticities by criterion and segment of analysis of the CBSI towards changes in the crisp values of each element, in terms of percentage change variation (Eqn 6). This information allows to understand how a change on the crisp values per each particular criterion and segment of analysis, impact on the CBSI; finding out, for example, which countries or generations should be given more attention in order to have the biggest impact on the consumption and buying of FAPs in the EU, in order to enhance the market of these products.

$$
\eta_{s, p, q}=\frac{\Delta \% \mathrm{CBSI}_{s, p}}{\Delta \% \mathrm{CV}_{s, p, q}} \text { with } s: 1, \ldots, s ; p: 1, \ldots, p \text { and } q: 1, \ldots, q
$$

In general, the fuzzy methodology requires the steps summarized in Figure 1. 


\section{Application of the methodology and results}

The application of the methodology for the case of the frequency of consumption at home, consumption outside home and buying of FAPs is shown as followed step by step. Initially, after the frequencies were converted into TFNs (step 1), means values of the TFNs were estimated per each segment of analysis and criterion (step 2) and then, for each one of them, crisps values were calculated (step 3).

Findings from the first three steps indicate that in the EU28, the most important place of consumption for FAPs, the consumption at home is around 56.34 times a year; while the consumption at restaurants or other food outlets is around 19.82 times a year; and the buying behavior of respondents is around 50.26. times a year. This indicates that home consumption is the most frequent one. The disparity observed between the consumption and the buying behavior indicates that in the EU28, around $34 \%$ of the times that FAPs are consumed, the products were not directly bought by the respondents. Table 3 also shows that Spain has the highest frequency of consumption at home and outside home with 93.47 and 37.36 times a year respectively, while Hungary has the lowest consumption of both at home and outsidehome with 15.97 and 6.62 times a year respectively. In addition, Spain has the highest frequency of buying FAPs at 85.36 times a year, while Hungary has the lowest with 12.66 times a year.

On step 4, the best positive and negative ideal solutions were determined (Table 3), as well as the percentage of variation for the different attributes. On one side, the best positive and negative ideal solutions indicate which elements are the best and worst evaluated for the different criterions; while the percentage of variation indicate how homogeneous or heterogeneous are each one of the elements studied. Results, in general, show that all the attributes are highly heterogeneous, with a percentage of variation of at least $485 \%$, which indicates that the EU market for FAPs is highly heterogeneous, and many factors cause this observed heterogeneity.

1. Convert the information of the frequencies of consumption (linguistic variable) per individual into triangular fuzzy numbers (TFNs)

\section{Estimate the mean triangular fuzzy numbers (TFNs) per segment of analysis} and criterion

1.3. Estimate the crisp values per segment of analysis and criterion

1.4. Determine the fuzzy ideal and negative-ideal solutions

1.5. Calculate the fuzzy distances of each of the segments of analysis in accordance to the ideal solutions

1.6. Estimate a consumption and buying synthetic indicators (CBSI) by segment of analysis and rank the alternatives according to them

\subsection{Calculate elasticities}

Consumption and buying behavior of

FAPs in EU28

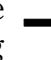


$\mathrm{BFJ}$

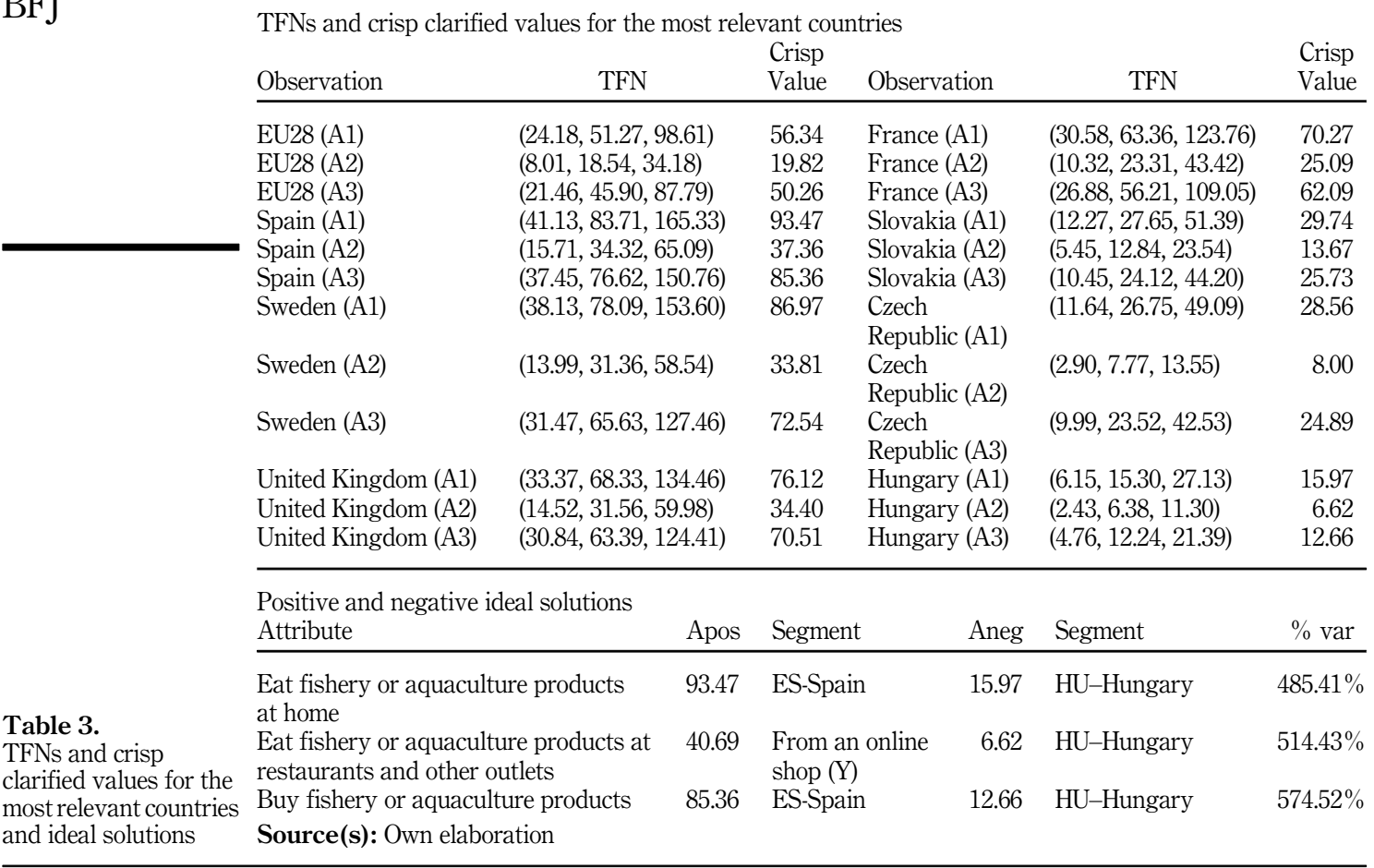

TFNs and crisp clarified values for the most relevant countries

Also, it was found that Spain and Hungary have the highest and lowest, respectively, consumption and buying patterns of FAPs, being thus identified as the positive and negative ideal solutions respectively in most of the cases. The only exception is for the positive ideal solution for consumption outside home, in which it was attributed to those who buy their products online, with around 40.69 times a year.

After that, the fuzzy distances of each element of the segment of analysis in accordance to the ideal solutions were calculated (step 5); and based on that, a consumption and buying synthetic indicator (CBSI) by country and generation was estimated and used to rank the elements (step 6). The obtained results indicate that Spain occupies the highest rank and Hungary the lowest; while for the generations, the highest indicator corresponds to the generation between 1928 and 1945, while the youngest generation, which corresponds to the one born after 1980, has the lowest indicator (Table 4).

Finally, in step 7, the elasticities of CBSI by country and generation (Table 5) were calculated. This analysis is helpful because it allows policymakers and the different stakeholders to prioritize or focus their efforts in some countries and generations, in which the designed policies could have a bigger impact. In general, we found that the CBSI is inelastic with respect to all the attributes for almost all the countries, except for the Czech Republic regarding the consumption of FAPs at home. The same is also observed for the analysis based on the generations.

In addition, the analysis by country and generation indicate that higher elasticities for those consuming FAPs at home (A1) and buying FAPs (A3) are observed, while the lowest elasticities are those associated to the consumption of FAPs outside-home (A2). Particularly, for the case of the countries, the highest elasticities for consumption at home (A1) and buying 


\begin{tabular}{|c|c|c|c|c|c|c|}
\hline Rank & Segment & CBSI & Rank & Segment & CBSI & Consumption \\
\hline \multicolumn{6}{|l|}{ Countries } & behavior of \\
\hline 1 & ES-Spain & 0.97 & 16 & UE28 & 0.51 & \multirow{15}{*}{ FAPs in EU28 } \\
\hline 2 & SE-Sweden & 0.86 & 17 & LT-Lithuania & 0.45 & \\
\hline 3 & GB-UKM-Great Britain & 0.79 & 18 & IT-Italy & 0.44 & \\
\hline 4 & FI-Finland & 0.76 & 19 & BE-Belgium & 0.44 & \\
\hline 5 & PT-Portugal & 0.76 & 20 & DE-E Germany East & 0.43 & \\
\hline 6 & LU-Luxembourg & 0.73 & 21 & DE-W-Germany-West & 0.40 & \\
\hline 7 & DK-Denmark & 0.72 & 22 & HR-Croatia & 0.36 & \\
\hline 8 & EE-Estonia & 0.70 & 23 & PL-Poland & 0.35 & \\
\hline 9 & NL-The Netherlands & 0.68 & 24 & BG-Bulgaria & 0.26 & \\
\hline 10 & FR-France & 0.68 & 25 & AT-Austria & 0.26 & \\
\hline 11 & GR-Greece & 0.64 & 26 & RO-Romania & 0.25 & \\
\hline 12 & CY-Cyprus (Republic) & 0.63 & 27 & SI-Slovenia & 0.24 & \\
\hline 13 & MT-Malta & 0.62 & 28 & SK-Slovakia & 0.18 & \\
\hline 14 & IE-Ireland & 0.58 & 29 & CZ-Czech Republic & 0.16 & \\
\hline 15 & LV-Latvia & 0.53 & 30 & HU-Hungary & 0.00 & \\
\hline \multicolumn{6}{|l|}{ Generation } & \multirow{5}{*}{$\begin{array}{r}\text { Table } 4 . \\
\text { Consumption and } \\
\text { buying synthetic } \\
\text { indicator by country } \\
\text { and generation }\end{array}$} \\
\hline 1 & $1928-1945$ & 0.59 & 4 & Before 1928 & 0.56 & \\
\hline 2 & Before 1946 & 0.59 & 5 & $1965-1980$ & 0.51 & \\
\hline 3 & $1946-1964$ & 0.57 & 6 & After 1980 & 0.39 & \\
\hline \multicolumn{6}{|c|}{ Source(s): Own elaboration } & \\
\hline
\end{tabular}

(A3) were related to the Czech Republic, while for the generations, they were attributed to the generation born after 1980. In addition, the highest elasticities related to the consumption outside-home of the products for the countries and generations were for Spain and the generation born after 1980, respectively.

\section{Discussion}

The CBSI exposed that the countries with the lowest indicator, and therefore those with the lowest consumption and buying frequency for FAPs in Europe, correspond to those located in the Central-Eastern part of the EU, while the ones with the highest CBSI are related to some countries of the Southern part of the EU and the Northern subregion.

Moreover, the elasticity analysis per country showed higher elasticities for at-home consumption of FAPs (A1) for the countries of Czech Republic, Slovakia, Slovenia, Romania, Austria and Bulgaria, which are countries located in the Central-Eastern zone of the EU (Figure 2). This indicates that marketing strategies directed to enhanced at-home consumption of these products, will have a bigger impact in the mentioned countries, therefore, policymakers and the different stakeholders must prioritize their attention into this geographic area, considering that most consumption of FAPs takes place at home in the EU, with around $70 \%$ of people consuming these products at home at least once a month, while $41 \%$ do it at least once a week (European Union, 2018b).

Similarly, as shown in Figure 3, it was found that Spain and Slovakia have the highest elasticities of CBSI by country towards the consumption of FAPs outside-home. Given the impact, restaurants and food outlets for these countries should invest on the search for solutions and strategies like product differentiation, in order to increase the willingness to eat for these products outside-home, especially in Spain, which has the highest consumption at home of the whole EU28. In this case, the challenge is to bring that appreciation for FAPs outside-home too.

In addition, as shown in Figure 4, there are similarities between the countries that have the highest elasticities of CSBI by country for buying FAPs and those associated with the 
$\mathrm{BFJ}$

Elasticities of CBSI by country

\begin{tabular}{|c|c|c|c|}
\hline Country & $\mathrm{A} 1$ & $\mathrm{~A} 2$ & A3 \\
\hline EU28 & 0.687 & 0.107 & 0.575 \\
\hline FR-France & 0.619 & 0.123 & 0.530 \\
\hline BE-Belgium & 0.710 & 0.135 & 0.590 \\
\hline NL-The Netherlands & 0.605 & 0.119 & 0.506 \\
\hline DE-W - Germany-West & 0.748 & 0.066 & 0.635 \\
\hline IT-Italy & 0.704 & 0.144 & 0.585 \\
\hline LU-Luxembourg & 0.638 & 0.099 & 0.513 \\
\hline DK-Denmark & 0.564 & 0.128 & 0.497 \\
\hline IE-Ireland & 0.650 & 0.122 & 0.561 \\
\hline GB-UKM - Great Britain & 0.629 & 0.110 & 0.513 \\
\hline GR-Greece & 0.579 & 0.081 & 0.490 \\
\hline ES-Spain & 0.131 & 0.330 & 0.110 \\
\hline PT-Portugal & 0.558 & 0.121 & 0.554 \\
\hline DE-E Germany East & 0.737 & 0.075 & 0.612 \\
\hline FI-Finland & 0.558 & 0.143 & 0.497 \\
\hline SE-Sweden & 0.426 & 0.146 & 0.587 \\
\hline AT-Austria & 0.864 & 0.201 & 0.667 \\
\hline CY-Cyprus (Republic) & 0.636 & 0.115 & 0.540 \\
\hline CZ-Czech Republic & 1.147 & 0.054 & 0.966 \\
\hline EE-Estonia & 0.558 & 0.105 & 0.462 \\
\hline HU-Hungary & Inf & $\operatorname{Inf}$ & Inf \\
\hline LV-Latvia & 0.678 & 0.079 & 0.558 \\
\hline LT-Lithuania & 0.714 & 0.055 & 0.599 \\
\hline MT-Malta & 0.644 & 0.121 & 0.544 \\
\hline PL-Poland & 0.786 & 0.078 & 0.670 \\
\hline SK-Slovakia & 0.999 & 0.227 & 0.818 \\
\hline SI-Slovenia & 0.903 & 0.145 & 0.729 \\
\hline BG-Bulgaria & 0.825 & 0.176 & 0.724 \\
\hline RO-Romania & 0.882 & 0.105 & 0.751 \\
\hline HR-Croatia & 0.764 & 0.104 & 0.651 \\
\hline $\begin{array}{l}\text { Elasticities of CBSI by generation } \\
\text { Generation }\end{array}$ & $\mathrm{A} 1$ & A2 & A3 \\
\hline Before 1928 & 0.688 & 0.095 & 0.502 \\
\hline 1928-1945 & 0.637 & 0.083 & 0.535 \\
\hline Before 1946 & 0.638 & 0.083 & 0.535 \\
\hline 1946-1964 & 0.655 & 0.100 & 0.557 \\
\hline 1965-1980 & 0.675 & 0.123 & 0.580 \\
\hline After 1980 & 0.763 & 0.147 & 0.583 \\
\hline
\end{tabular}

Table 5.

Elasticities of CBSI by country and generation

consumption of FAP at home, which is expected considering that the buying behavior is highly correlated with at-home consumption.

Moreover, the finding that the highest value of the CBSI by generation corresponds to the older generations, and therefore, they have the highest frequency of consumption and buying of FAPs, is in accordance with some studies in the literature (Herrmann et al., 1994; Murray et al., 2017; Myrland et al., 2000; Thong and Solgaard, 2017).

Furthermore, the elasticity analysis by generation revealed that the highest values are related to the youngest generation (after 1980), therefore, it is important for future research to determine how the use of special marketing strategies applied to this particular generation, such as product differentiation and online shopping strategies, might enhance the consumption and buying of these products. 


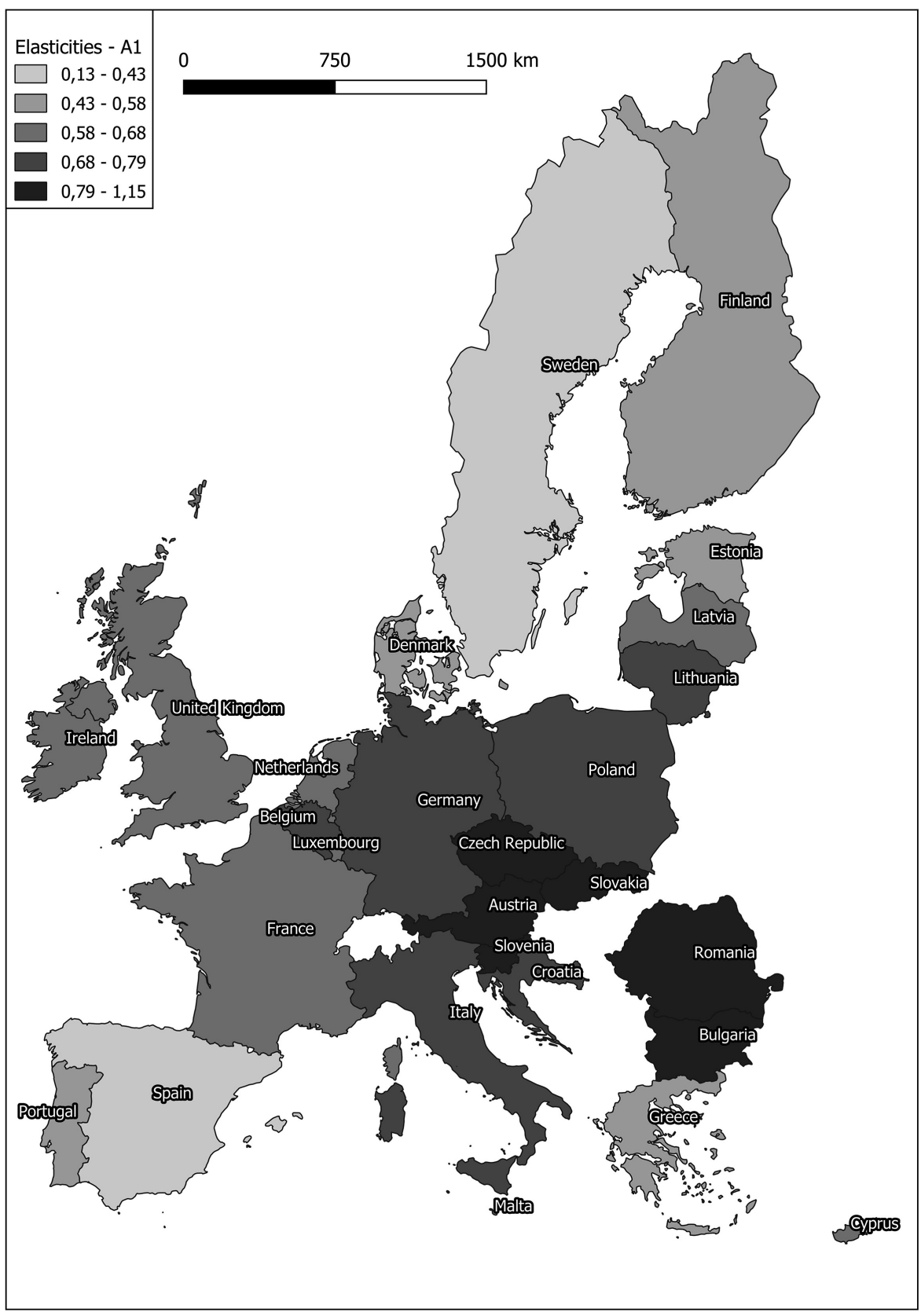

Consumption and buying behavior of

FAPs in EU28

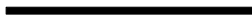

Figure 2. Elasticities of CBSI by country for the consumption of FAP at home

\section{Conclusions}

In this investigation, a hybrid fuzzy methodology was proposed to analyze and integrate both the consumption and buying behavior for FAPs in order to obtain a synthetic demand indicator denominated as consumption and buying synthetic indicator (CBSI) in the EU28, 


\section{$\mathrm{BFJ}$}

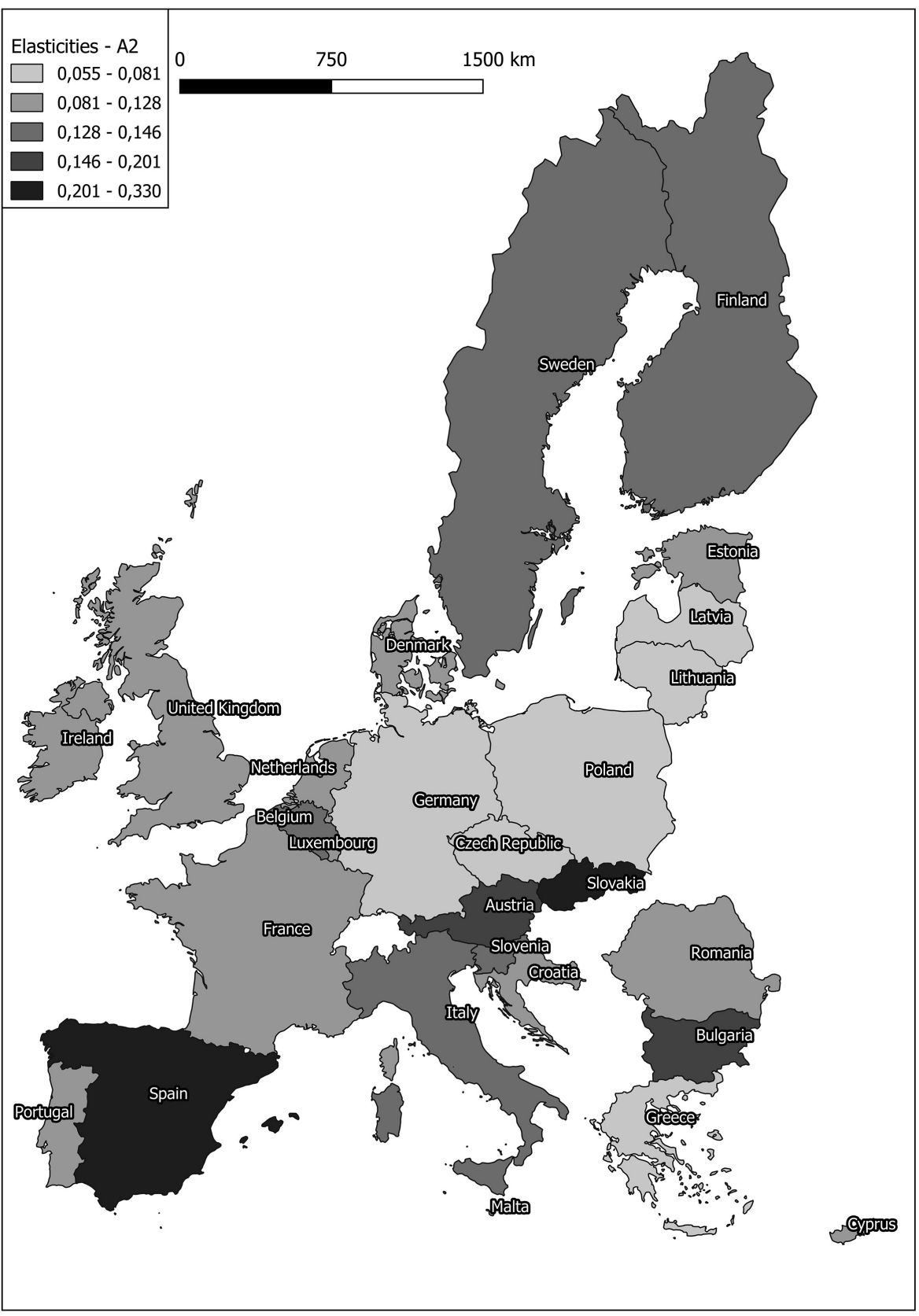

Figure 3.

Elasticities of CBSI by country for the consumption of FAP outside-home

based on the Eurobarometer survey (European Union, 2018b). The segment analysis is made at the level of different countries and generations. The findings indicate relevant differences that depend on the country of residence and the generation of the residents. 


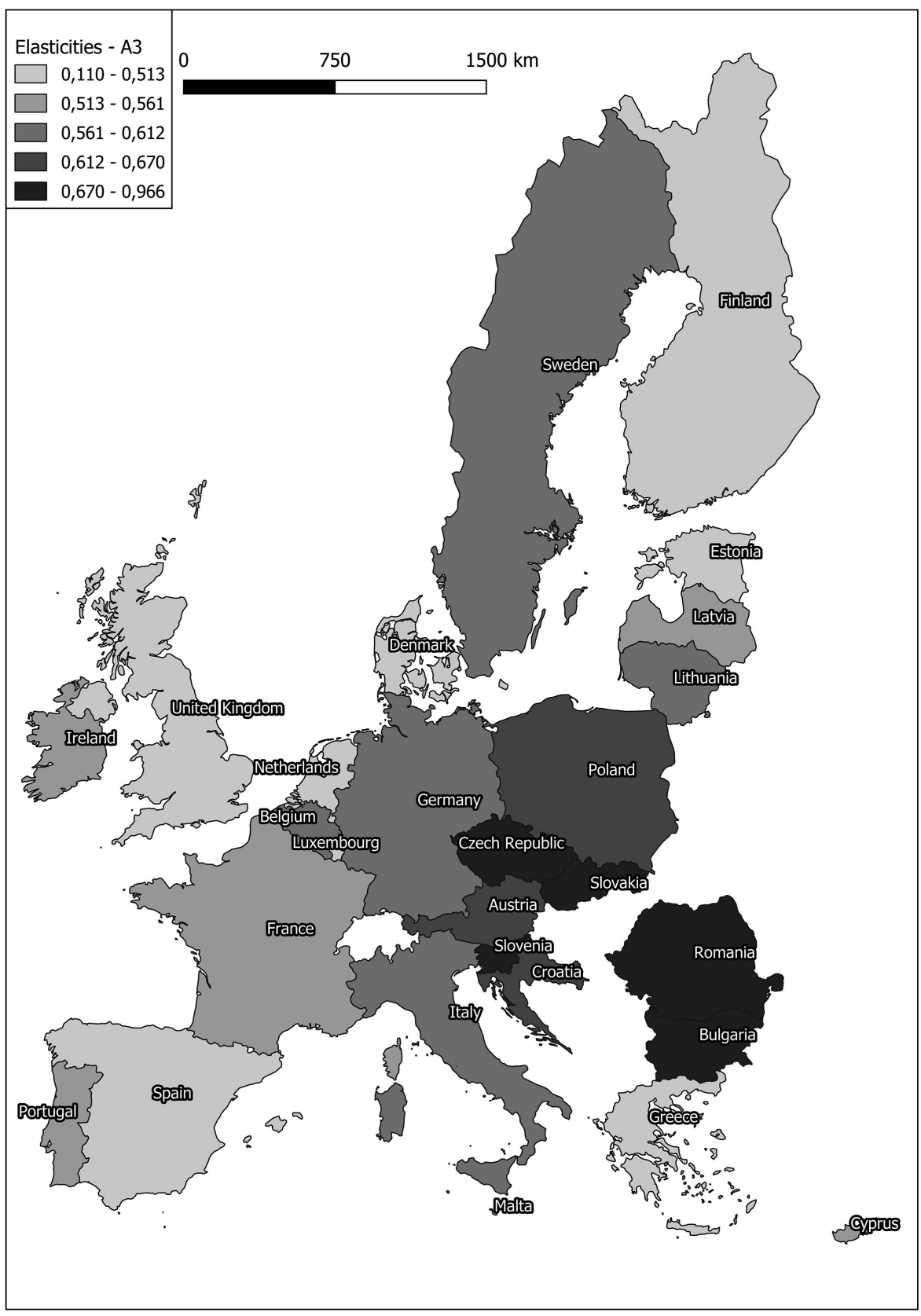

Consumption and buying behavior of

FAPs in EU28

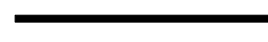

Figure 4.

Elasticities of CBSI by country for buying FAP

The results show that Spain has the highest consumption and buying patterns of FAPs in the $\mathrm{EU}$, while the lowest values correspond to Hungary. Moreover, the CBSI calculated by country indicates a clear disparity between them, in which there are higher values for some countries of 
the Southern part of the EU and the Northern subregion, and lower values for those located in the Central-Eastern part of the EU.

Furthermore, the indicator by generation displays that the highest value of the indicator corresponds to the generation of the residents born between 1928 and 1945, while the lowest is related to the youngest generation (born after 1980).

The elasticity analysis performed by country and generation evidenced that the CBSI is inelastic with respect to all the attributes for almost all countries and generations, except for the Czech Republic in relationship with the consumption of FAPs at home. Nevertheless, it can be stated that higher elasticities of CBSI associated with those consuming at home and buying FAPs are observed, in comparison with the lower elasticities of CBSI obtained for the ones that consume FAPs outside-home.

Also, the elasticity analysis indicates that the highest elasticities of CSBI by country associated with the at home consumption and buying of FAPs were related to the countries located in the Central-Eastern zone of the EU. Therefore, it is recommended that policymakers and the different stakeholders to prioritize efforts on marketing strategies for these countries, because it will make the biggest impact. Likewise, the biggest impact on consumption of FAPs outside home according to the elasticity analysis is associated with Spain and Slovakia.

In addition, the results of the elasticity analysis by generation, indicate the highest elasticities of CBSI associated with consumption and buying of FAPs to the generation formed by the people born after 1980. This result shows the importance of future research to find effective ways to promote the consumption of FAPs in new generations.

\section{References}

Almeida, C., Altintzoglou, T., Cabral, H. and Vaz, S. (2015), "Does seafood knowledge relate to more sustainable consumption?”, British Food Journal, Vol. 117 No. 2, pp. 894-914.

Almendarez-Hernández, M.A.A., Avilés-Polanco, G., Beltrán-Morales, L.F. and Pérez-Ramirez, M.Y. (2015), "Determinantes en el consumo de atún en México aplicando modelos de elección ordenada", Interciencia, Vol. 40 No. 6, pp. 390-396.

Can, M.F., Günlü, A. and Can, H.Y. (2015), "Fish consumption preferences and factors influencing it", Food Science and Technology, Vol. 35 No. 2, pp. 339-346.

Cavaliere, A., De Marchi, E., Donzelli, F. and Banterle, A. (2019), "Is the mediterranean diet for all? An analysis of socioeconomic inequalities and food consumption in Italy", British Food Journal, Vol. 121 No. 6, pp. 1327-1341.

Chen, S.M. (1996), "Evaluating weapon systems using fuzzy arithmetic operations", Fuzzy Sets and Systems, Vol. 77 No. 3, pp. 265-276.

European Union (2018a), The EU Fish Market - 2018 Edition, available at: https://www.eumofa.eu/ documents/20178/132648/EN_The+EU+fish+market+2018.pdf (accessed 2 May 2019).

European Union (2018b), Special Eurobarometer 475: EU Consumer Habits Regarding Fishery and Aquaculture Products, available at: https://publications.europa.eu/en/publication-detail/-/ publication/0ddd87f3-dc82-11e6-ad7c-01aa75ed71a1 (accessed 26 April 2019).

FAO (2018), FAO Yearbook. Fishery and Aquaculture Statistics 2016, Food and Agriculture Organization of the United Nation, Rome, Italy.

Hall, T.E. and Amberg, S.M. (2013), "Factors influencing consumption of farmed seafood products in the Pacific northwest", Appetite, Vol. 66, pp. 1-9.

Herrmann, R.O., Rauniyar, G.P., Hanson, G.D. and Wang, G. (1994), "Identifying frequent seafood purchasers in the northeastern US", Agricultural and Resource Economics Review, Vol. 23 No. 2, pp. 226-235.

Higuchi, A., Dávalos, J., Hernani-Merino, M., Higuchi, A., Dávalos, J. and Hernani-Merino, M. (2017), "Theory of planned behavior applied to fish consumption in modern Metropolitan Lima", Food Science and Technology, Vol. 37 No. 2, pp. 202-208. 
Islam, M.J., Sayeed, M.A., Akhtar, S., Hossain, M.S. and Liza, A.A. (2018), "Consumers profile analysis towards chicken, beef, mutton, fish and egg consumption in Bangladesh", British Food Journal, Vol. 120 No. 12, pp. 2818-2831.

Kumar, G., Quagrainie, K. and Engle, C. (2008), "Factors that influence frequency of purchase of catfish by US households in selected cities", Aquaculture Economics and Management, Vol. 12 No. 4, pp. 252-267.

Lee, M.K. and Nam, J. (2019), "The determinants of live fish consumption frequency in South Korea", Food Research International, Vol. 120, pp. 382-388.

Murray, G., Wolff, K. and Patterson, M. (2017), "Why eat fish? Factors influencing seafood consumer choices in British Columbia, Canada”, Ocean and Coastal Management, Vol. 144, pp. 16-22.

Myrland, Ø., Trondsen, T., Johnston, R.S. and Lund, E. (2000), "Determinants of seafood consumption in Norway: lifestyle, revealed preferences, and barriers to consumption", Food Quality and Preference, Vol. 11 No. 3, pp. 169-188.

Quagrainie, D.K. (2006), "IQF catfish retail pack: a study of consumers' willingness to pay", International Food and Agribusiness Management Review, Vol. 9, pp. 75-87.

Rortveit, A.W. and Olsen, S.O. (2007), "The role of consideration set size in explaining fish consumption”, Appetite, Vol. 49 No. 1, pp. 214-222.

Rortveit, A.W. and Olsen, S.O. (2009), "Combining the role of convenience and consideration set size in explaining fish consumption in Norway", Appetite, Vol. 52 No. 2, pp. 313-317.

Santeramo, F.G., Carlucci, D., De Devitiis, B., Nardone, G. and Viscecchia, R. (2017), "On consumption patterns in oyster markets: the role of attitudes", Marine Policy, Vol. 79, pp. 54-61.

Thong, N.T. and Olsen, S.O. (2012), "Attitude toward and consumption of fish in vietnam", Journal of Food Products Marketing, Vol. 18 No. 2, pp. 79-95.

Thong, N.T. and Solgaard, H.S. (2017), "Consumer's food motives and seafood consumption”, Food Quality and Preference, Vol. 56, pp. 181-188.

Tomić, M., Matulić, D. and Jelić, M. (2016), "What determines fresh fish consumption in Croatia?", Appetite, Vol. 106, pp. 13-22.

Tuu, H.H., Olsen, S.O., Thao, D.T. and Anh, N.T.K. (2008), "The role of norms in explaining attitudes, intention and consumption of a common food (fish) in Vietnam", Appetite, Vol. 51 No. 3, pp. 546-551.

Vanhonacker, F., Altintzoglou, T., Luten, J. and Verbeke, W. (2011), "Does fish origin matter to European consumers? Insights from a consumer survey in Belgium, Norway and Spain”, British Food Journal, Vol. 113 No. 4, pp. 535-549.

Verbeke, W. and Vackier, I. (2005), "Individual determinants of fish consumption: application of the theory of planned behavior", Appetite, Vol. 44 No. 1, pp. 67-82.

Yousuf, J.B., Bose, S., Kotagama, H. and Boughanmi, H. (2019), "Preferences and intentions of seafood consumers in Oman: an empirical analysis", Journal of International Food and Agribusiness Marketing, Vol. 31 No. 2, pp. 175-203.

\section{Corresponding author}

Javier Cantillo can be contacted at: javier.cantillo101@alu.ulpgc.es

For instructions on how to order reprints of this article, please visit our website:

www.emeraldgrouppublishing.com/licensing/reprints.htm

Or contact us for further details: permissions@emeraldinsight.com 